
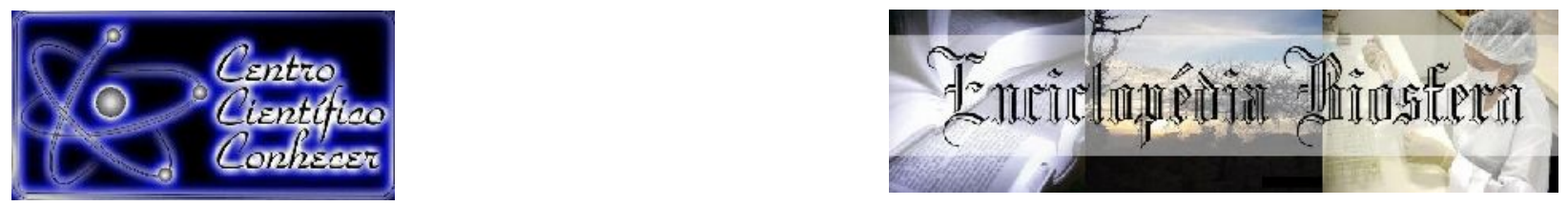

\title{
ASPECTOS DA QUALIDADE DE FARINHAS DE MANDIOCA (Manihot esculenta Crantz) ARTESANAIS PRODUZIDAS NO MUNICÍPIO DE SANTANA DE PIRAPAMA/MG
}

Leonara Martins Viana ${ }^{1}$, Christiano Vieira Pires ${ }^{2}$, Maria Clara Coutinho Macedo ${ }^{3}$, Felipe Machado Trombete ${ }^{4}$,Luana Sousa Silva ${ }^{5}$

1 Graduada em Engenharia de Alimentos pela Universidade Federal de São João Del Rei, Sete Lagoas-Brasil

2 Professor Doutor do Departamento de Engenharia de Alimentos da Universidade Federal de São João Del Rei (christiano@ufsj.edu.br)

3 Doutoranda em Ciência de Alimentos pela Universidade Federal de Minas Gerais

4 Professor Doutor do Departamento de Engenharia de Alimentos da Universidade

Federal de São João Del Rei

5 Técnica de Laboratório do Departamento de Engenharia de Alimentos da Universidade Federal de São João Del Rei

\section{Recebido em: 04/10/2019 - Aprovado em: 30/11/2019 - Publicado em: 15/12/2019 DOI: 10.18677/EnciBio_2019B4}

\begin{abstract}
RESUMO
A mandioca (Manihot esculenta Crantz) é um tubérculo com importante destaque devido a sua vasta utilidade. Essa matéria-prima é utilizada na produção de inúmeros produtos, tal como a farinha de mandioca, que se sobressai por ser um derivado de grande importância alimentar, contudo apresenta pouca padronização devido ao processamento artesanal. Sendo assim, o presente estudo avaliou a qualidade de farinhas de mandioca produzidas por diferentes produtores do município de Santana de Pirapama/MG, caracterizando aspectos físico-químicos (umidade, cinzas, lipídeos, proteínas, carboidratos, acidez, cor, granulometria), nutricionais (valor energético), bem como a contagem de bolores e leveduras, além da pesquisa de matérias estranhas. Foram analisadas 12 amostras de farinhas coletadas em seis unidades produtoras, do município de Santana de Pirapama/MG, em dois períodos de 2018. A partir da análise dos resultados, verificou-se que as farinhas se encontravam dentro das normas de qualidade exigidas em legislação, quanto aos parâmetros físico-químicos e nutricionais. Já as características de maior influência na discriminação das farinhas foram à acidez e cinzas, indicando que a forma de produção tem influência direta na qualidade do produto final. As farinhas se caracterizaram como claras, já a contagem de bolores e leveduras nas amostras de farinha foram baixas, entretanto não existe legislação que regulamente a contagem dos mesmos em farinhas. Quanto a avaliação microscópica, 90\% das farinhas continham a presença de matérias estranhas. Boas práticas de fabricação podem oferecer uma redução das irregularidades no processo produtivo e de distribuição, além de contribuir para uma maior segurança alimentar para o consumo desse produto.
\end{abstract}

PALAVRAS-CHAVE: legislação, matéria estranha, tuberosa. 


\title{
QUALITY OF FLOUR OF CASSAVA (Manihot esculenta Crantz) CRAFTS PRODUCED IN THE MUNICIPALITY OF SANTANA DE PIRAPAMA/MG
}

\begin{abstract}
Cassava (Manihot esculenta Crantz) is a tuber with important highlight due your vast utility. This raw material is used in the production of numerous products, such as manioc flour, which stands out for being a derivative of great importance, however food presents very little standardization due to small-scale processing. Thus, the present study evaluated the quality of cassava flour produced by different producers of Santana de Pirapama, Minas Gerais, characterizing physicochemical aspects (moisture, ash, lipids, proteins, carbohydrates, acidity, color, particle size), nutritional (energy value), as well as the count of yeasts and molds, as well as the research of foreign matter. 12 flour samples were analyzed, collected in six units, of Santana de Pirapama, Minas Gerais, in two periods of 2018. From the analysis of the results, it was found that the flours were inside of the quality standards required in legislation, as the physico-chemical and nutritional parameters. Already the features of greatest influence on breakdown of flour were acidity and ash, indicating that the form of production has a direct influence on the quality of the final product. The flour if characterized as clear, already count of yeasts and molds in flour samples were low, however there is no legislation regulating the count them in flour. As microscopic evaluation, $90 \%$ of the flour contained the presence of extraneous matter. Good manufacturing practices may offer a reduction of irregularities in the process of production and distribution, as well as contribute to greater food security for the consumption of this product.
\end{abstract}

KEYWORDS: legislation, foreign matter, tuberous.

\section{INTRODUÇÃO}

As tuberosas são plantas que se desenvolvem abaixo da superfície do solo, sendo domesticadas principalmente nas terras baixas da América Central e do Sul. Entre o vasto conjunto de tuberosas a mandioca (Manihot esculenta Cranz) é a espécie que se destaca por ser uma matéria prima com muitos usos, além de desempenhar importante papel socioeconômico (agricultura familiar) nos locais de produção (MATTOS et al., 2006).

De acordo com a Embrapa (2016), a mandioca é produzida em todo território nacional, e está entre os oitos produtos agrícolas com maior área de cultivo e posicionada na sexta posição em produtividade. No Brasil, somente o estado de Minas Gerais produziu cerca de $820 \mathrm{mil} /$ toneladas de mandioca em 2018, o que corresponde a um total de 57,7 mil hectares de áreas plantadas, demonstrando assim a participação significativa da região Sudeste na produção brasileira (SEAPA, 2018).

A mandioca possui grande versatilidade, podendo ser utilizada na alimentação humana e animal, com diversas possibilidades de industrialização, como a farinha das raízes e folhas, polvilho, amido e fécula (ÁLVARES et al., 2016). A farinha de mandioca é o produto obtido de raízes do gênero Manihot, submetidas ao processo tecnológico adequado de fabricação e beneficiamento (BRASIL, 2011).

Apesar da farinha ser considerada a forma mais ampla de aproveitamento industrial da mandioca, é um produto pouco valorizado, principalmente pela falta de padronização da fabricação e pela elevada variabilidade no mercado, o que dificulta 
a comercialização (ÁLVARES et al., 2016).Em sua grande maioria os produtores de farinha de mandioca, desenvolvem tais produtos com 0 intuito de obter 0 aproveitamento das raízes de mandioca e assim adquirir uma renda fixa por meio da comercialização das mesmas (SIQUEIRA et al., 2015).

O modo de fabricação artesanal deste produto preocupa quanto a adequação à legislação vigente, isto porque ao se referir à qualidade da farinha, os aspectos sociais, culturais e de legalidade estão intimamente associados ao grau de qualidade do produto obtido. Por isto, a produção de farinha de mandioca artesanal ainda encontra obstáculos na cadeia produtiva, especialmente quanto aos atributos físico-químicos, e classificação comercial contidos na legislação brasileira (ÁLVARES et al., 2016).

No município de Santana de Pirapama no estado de Minas Gerais, as farinhas de mandioca são fabricadas pelos produtores de forma totalmente artesanal, sendo uma atividade de grande importância social e econômica para uma significativa parte da população rural deste município. Dessa forma, verifica-se a necessidade da realização de pesquisas associadas a farinha de mandioca, visto o grande significado social, nutricional e econômico deste produto.

O presente trabalho teve como objetivo avaliar a qualidade de farinhas de mandioca de diferentes produtores de agricultura familiar do município de Santana de Pirapama- MG, caracterizando as mesmas, quanto a composição nutricional, parâmetros físico-químicos, contagem de bolores, leveduras, presença de matérias estranhas e sujidades leves.

\section{Amostragem}

\section{MATERIAL E MÉTODOS}

Foram coletadas 12 amostras de farinhas de mandioca (Manihot esculenta Crantz) artesanais do grupo seca, em seis unidades produtoras do município de Santana de Pirapama- MG. As farinhas foram coletadas de acordo com o número de sacos a serem amostrados, e dependendo do tamanho do lote. Assim, para até 10 sacos de farinha, todos os sacos ou fardos foram amostrados, coletando-se a quantidade do produto que constitui o lote (sacos ou fardos) (BRASIL, 2011).

A coleta das amostras foi feita com equipamento apropriado (conchas esterilizadas), colocando-se aproximadamente $30 \mathrm{~g}$ de farinha por saco até completar o volume mínimo em $1 \mathrm{~kg}$ do produto para cada fração de, no máximo, seis sacos, as amostras foram acondicionadas em sacos plásticos de primeiro uso. Por fim, a quantidade de farinha extraída foi homogeneizada, quarteada e reservada para comporem a amostra que foi analisada em base úmida.

As farinhas foram adquiridas nos meses de abril e setembro de 2018 e foram identificadas como período 1 (P1) e período 2 (P2), respectivamente. O tempo entre a coleta das amostras e as análises laboratoriais variou de acordo com a logística de coleta e a distância até o local de realização da análise sendo de 12 a 24 horas para os distritos mais próximos (Curralinho, Gerais e Tibuna). As amostras foram encaminhadas para o Laboratório de Análises de Alimentos, Laboratório de Microbiologia de Alimentos e Laboratório de Microscopia do Departamento de Engenharia de Alimentos da Universidade Federal de São João del-Rei, Campus Sete Lagoas- MG, onde foram analisadas em triplicata. 


\section{Análises Físico-Químicas}

Para a realização das análises as amostras eram pré-homogeneizadas e dividida em quatro partes iguais, sendo tomadas duas partes opostas entre si para constituir uma nova amostra e descartadas as partes restantes. As partes não descartadas foram misturadas totalmente e o processo de quarteamento foi repetido até que se obtivesse a massa desejada para as análises (ÁLVARES, 2016).

As determinações de umidade, cinzas, lipídeos, acidez titulável, proteínas, carboidratos e valor energético foram realizadas segundo a metodologia proposta pelo Instituto Adolfo Lutz (IAL,2008). A acidez titulável, em meq NaOH.100 g $\mathrm{g}^{-1}$, foi realizada por meio de titulação, utilizando-se $\mathrm{NaOH} 0,05 \mathrm{~N}$. Já os carboidratos totais, em porcentagem (\%), foram estimados por diferença, subtraindo-se de $100 \mathrm{~g} \mathrm{o}$ somatório de proteínas, lipídeos, cinzas e umidade. O valor energético foi calculado a partir dos coeficientes calóricos (proteínas, carboidratos e gordura), utilizando-se a seguinte fórmula: VE $=[($ Proteínas $(\mathrm{g}) \times 4 \mathrm{kcal})]+[($ Carboidratos totais $(\mathrm{g}) \times 4 \mathrm{kcal})]$ $+[($ Lipídeos $(\mathrm{g}) \times 9 \mathrm{kcal})]$.

\section{Análise Colorimétrica}

Os parâmetros colorimétricos foram avaliados com o auxílio de um colorímetro Konica Minolta, CR410. Os resultados foram expressos em valores de $L^{*}, a^{*}$ e $b^{*}$, em que os valores de $L^{*}$ (luminosidade ou brilho) variam do preto (0) ao branco (100), os valores do croma* variam do verde $(-60)$ ao vermelho $(+60)$ e os valores do croma $b^{*}$ variam do azul ao amarelo, ou seja, de -60 a +60 , respectivamente. A leitura foi realizada em três pontos distintos da cubeta, e o resultado final foi feito a partir da média entre as três leituras da amostra.

\section{Análise Granulométrica}

Para a determinação do tamanho dos grânulos das farinhas foi utilizado um agitador de peneiras Lucadema Modelo Luca 04/01, composto de duas peneiras com abertura de malha nominal igual a $1 \mathrm{~mm}$ (um milímetro) e $2 \mathrm{~mm}$ (dois milímetros) de diâmetro do aro externo, onde se colocou $100 \mathrm{~g}$ de farinha em agitação por um minuto na velocidade máxima (10 dimmer), anotando-se a quantidade de amostra retida em cada peneira.

\section{Pesquisa de Matéria Estranha e Sujidades Leves}

Para a pesquisa microscópica foram seguidos os procedimentos do método 970.66 da AOAC - Association of Official Analytical Chemists (AOAC, 2016), para isolamento de matérias estranhas e sujidades leves ("partículas de sujidades mais leves, oleofílicas, separadas dos alimentos pela flutuação, numa mistura líquida óleo água, como por exemplo: fragmentos de insetos, insetos inteiros, ácaros, pelo de roedor e bárbulas de aves") (DIMOV et al., 2004). As amostras contendo $225 \mathrm{~g}$ de farinha de mandioca foram adicionadas em frasco armadilha de Wildman de 1000 $\mathrm{mL}$ e adicionadas de $600 \mathrm{~mL}$ de álcool (40\%) e $30 \mathrm{~mL}$ de óleo mineral, sendo então levada a ebulição por cinco minutos, com agitação manual durante tal período. Após isto, deixou-se esfriar e o óleo mineral foi coletado e filtrado através de papel filtro qualitativo (125 mm, Unifil), com auxílio de vácuo (Bomba Marconi MA059). Por mais duas vezes foram adicionados $30 \mathrm{~mL}$ de óleo mineral ao frasco de Wildman e completado o volume com álcool (40\%), e o processo foi repetido. O filtro de papel contendo os fragmentos retidos foi transferido para uma placa de Petri, identificado e congelado até o momento das observações microscópicas. 
Para a identificação dos fragmentos retidos no filtro foi utilizado um microscópio estereoscópio (ZEISS Primo Star), e um microscópio ótico (ZEISS Stemi 2000-C) ambos acoplados com câmera (ZEISS Axiocam ERc5s). Inicialmente, procedeu-se a observação no estereoscópio com aumento de sete vezes. Os fragmentos foram então coletados com auxílio de palito de madeira e glicerina, sendo transferidos para lâminas contendo água destilada e cobertos com lamínula, a fim de confirmação no microscópio ótico (quando necessário), utilizando aumento de 40,100 e 400 vezes. A identificação dos fragmentos de insetos, pelos e demais matérias estranhas e sujidades basearam-se nas referências de Barbieri (2001) e Oliveira et al., (2015).

\section{Pesquisa de Bolores e Leveduras}

Foi realizada a contagem de fungos totais nas amostras de farinha de mandioca. Para isso, foram pesados 25 gramas de cada uma das amostras e adicionados $225 \mathrm{~mL}$ de água peptonada $0,1 \%$. Após a homogeneização, foram realizadas diluições decimais seriadas e foram plaqueadas $0,1 \mathrm{~mL}$ de amostra em Ágar Batata Glicose (ABG) e incubadas por cinco dias a $25^{\circ} \mathrm{C}$ em BOD. As colônias foram contadas e multiplicadas pelo fator de diluição, como descrito pela metodologia de Silva et al., (2010).

\section{Análise de Dados}

A partir dos resultados obtidos, foram calculadas as médias seguidas de desvio padrão, para todas as amostras de farinha de mandioca.

\section{RESULTADOS E DISCUSSÃO}

Os resultados médios encontrados para as análises físico-químicas das farinhas de mandioca coletadas nos meses de abril (P1) e setembro (P2), estão apresentados na Tabela 1.

TABELA 1. Valores médios dos resultados das análises de composição centesimal das amostras de farinhas de mandioca coletadas nos períodos 01 e 02 (abril/P1 e setembro/P2).

\begin{tabular}{ccccccc}
\hline \multirow{2}{*}{ Farinhas } & \multicolumn{2}{c}{ Umidade (\%) } & \multicolumn{2}{c}{ Proteína (\%) } & \multicolumn{2}{c}{ Cinzas (\%) } \\
\cline { 2 - 7 } & P1 & P2 & P1 & P2 & P1 & P2 \\
\hline F1 & $12,55 \pm 0,29$ & $10,41 \pm 0,43$ & $1,14 \pm 0,57$ & $1,68 \pm 0,84$ & $1,01 \pm 0,08$ & $0,88 \pm 0,05$ \\
F2 & $12,72 \pm 1,34$ & $9,77 \pm 0,77$ & $1,6 \pm 0,03$ & $1,09 \pm 0,12$ & $1,11 \pm 0,08$ & $1,40 \pm 0,16$ \\
F3 & $8,49 \pm 0,19$ & $9,11 \pm 0,47$ & $1,37 \pm 0,10$ & $1,4 \pm 0,08$ & $1,31 \pm 0,29$ & $1,43 \pm 0,10$ \\
F4 & $9,99 \pm 0,15$ & $10,04 \pm 0,81$ & $1,34 \pm 0,05$ & $1,45 \pm 0,07$ & $1,66 \pm 0,08$ & $1,32 \pm 0,07$ \\
F5 & $9,67 \pm 0,62$ & $8,53 \pm 0,06$ & $1,08 \pm 0,08$ & $1,3 \pm 0,02$ & $1,55 \pm 0,21$ & $1,36 \pm 0,06$ \\
F6 & $9,02 \pm 0,69$ & $8,13 \pm 0,15$ & $1,11 \pm 0,19$ & $1,55 \pm 0,28$ & $1,27 \pm 0,43$ & $1,21 \pm 0,08$
\end{tabular}

Legenda: F1 = Farinha 1, F2 = Farinha 2, F3 = Farinha 3, F4 = Farinha 4, F5 = Farinha 5 e F6 = Farinha 6.

Continuação Tabela 1

\begin{tabular}{ccccc}
\hline \multirow{2}{*}{ Farinhas } & \multicolumn{2}{c}{ Lipídeo (\%) } & \multicolumn{2}{c}{ Carboidrato (\%) } \\
\cline { 2 - 5 } & P1 & P2 & P1 & P2 \\
\hline F1 & $0,16 \pm 0,02$ & $0,36 \pm 0,06$ & $85,14 \pm 0,01$ & $86,69 \pm 0,09$ \\
F2 & $0,18 \pm 0,02$ & $0,47 \pm 0,07$ & $83,64 \pm 0,09$ & $87,24 \pm 1,13$
\end{tabular}




$\begin{array}{lllll}\text { F3 } & 0,14 \pm 0,06 & 0,60 \pm 0,03 & 88,69 \pm 0,08 & 84,50 \pm 0,03 \\ \text { F4 } & 0,24 \pm 0,02 & 0,46 \pm 0,04 & 86,78 \pm 0,12 & 86,72 \pm 0,05 \\ \text { F5 } & 0,51 \pm 0,02 & 0,45 \pm 0,02 & 87,19 \pm 0,01 & 88,35 \pm 0,008 \\ \text { F6 } & 0,19 \pm 0,01 & 0,33 \pm 0,002 & 88,42 \pm 0,40 & 88,78 \pm 0,09\end{array}$

Legenda: F1 = Farinha 1, F2 = Farinha 2, F3 = Farinha 3, F4 = Farinha 4, F5 = Farinha 5 e F6 = Farinha 6.

A determinação do teor de umidade demonstrou que todas as amostras estavam dentro dos valores estabelecidos pela legislação brasileira, que determina um valor máximo de 13\% (BRASIL, 2011). A umidade é um fator de grande importância, pois representa um dos principais motivos de aceleração de reações químicas e enzimáticas, podendo assim, afetar a qualidade final do produto. De acordo com Giacomelli et al., (2012) as condições de acondicionamento dos produtos, durante o período de comercialização podem colaborar para alterações no teor de umidade, podendo este ser então um dos fatores para a diferença de umidade apresentada entre as farinhas.

Os teores médios de cinzas variaram de 1,01 a 1,66\% para $\mathrm{P} 1$ e 0,88 a 1,43 \% para P2. No trabalho de Silva et al., (2015), foi avaliado a classificação da farinha de mandioca Copioba produzida no Vale da Copioba/Recôncavo Baiano-BA, os mesmos encontratam teores de cinzas variando de $0,71 \%$ a $1,28 \%$, valores próximos aos observados nesse estudo.

Os resultados das amostras F5 (1,55\%), F4 (1,66\%) do período 1 e F3 $(1,43 \%)$ do período 2 estavam fora do padrão exigido pela a legislação, que determina o máximo de $1,4 \%$ de cinzas, o que demonstra que as mesmas podem ter sido alvo de processamento inadequado, variações de cultivar, época de colheita e solo, além da presença de matérias estranhas oriundas de locais onde as mandiocas foram descascadas (SILVA et al. 2015).

A Instrução Normativa $n^{\circ} 52$, de 7 de novembro de 2011, do Ministério da Agricultura, Pecuária e Abastecimento (MAPA) (BRASIL, 2011) não faz referência aos teores de proteínas e lipídeos na farinha de mandioca. Neste trabalho, os resultados entre as amostras variaram de 1,08 a 1,60\% (P1) e 1,09 a 1,68\% (P2) para proteínas, e 0,14 a 0,51\% (P1) e 0,35 a 0,60\% (P2) para lipídeos. De acordo com Cardoso filho et al., (2015) estes parâmetros podem variar em função das características intrínsecas das plantas.

Para a análise de carboidratos, os valores entre as amostras de farinhas variaram de $83,64 \%$ e $88,69 \%$ para o período 1 (P1) e $84,50 \%$ a $88,78 \%$ para 0 período 2 (P2). Esses parâmetros podem estar relacionados ao uso de diferentes variedades de raízes de tuberosas para a produção da farinha, bem como possíveis mudanças no processo de fermentação da massa de mandioca (ÁLVARES et al., 2016).

A acidez das farinhas variou entre 2,36 e 7,14 (P1) e 2,34 e 4,42 (P2) meq $\mathrm{NaOH} .100 \mathrm{~g} \mathrm{~g}^{-1}$. Conforme pode ser observado na Tabela 2, aproximadamente $70 \%$ das amostras, apresentaram níveis superiores de acidez, classificando-as como de "alta acidez" (> 3,0 meq NaOH. $100 \mathrm{~g}^{-1}$ ), apenas as amostras F1 $(2,54)$ e F5 $(2,34)$ do período 2, indicaram uma "acidez baixa" (<3,0 meq NaOH. $\left.100 \mathrm{~g}^{-1}\right)$. 
TABELA 2. Valores médios dos teores de acidez de amostras de farinhas de mandioca coletadas nos meses de abril e setembro (P1 e P2).

\begin{tabular}{llc}
\hline \multirow{2}{*}{ Farinhas } & \multicolumn{2}{c}{$\begin{array}{c}\text { Acidez } \text { (meq. } \mathbf{~ N a O H} \\
\mathbf{0 , 1} \mathbf{~ N} / \mathbf{1 0 0} \text { g) }\end{array}$} \\
\cline { 2 - 3 } & $\mathbf{P 1}$ & $\mathbf{P 2}$ \\
\hline F1 & $3,37 \pm 0,14$ & $2,54 \pm 0,15$ \\
F2 & $7,14 \pm 0,10$ & $4,32 \pm 0,30$ \\
F3 & $2,36 \pm 0,30$ & $2,47 \pm 0,10$ \\
F4 & $3,43 \pm 0,37$ & $4,42 \pm 0,20$ \\
F5 & $3,80 \pm 0,05$ & $2,34 \pm 0,15$ \\
F6 & $3,19 \pm 0,74$ & $4,29 \pm 0,30$ \\
\hline
\end{tabular}

Legenda: F1= Farinha 1, F2 = Farinha 2, F3 = Farinha 3, F4 = Farinha 4, F5 = Farinha 5 e F6 = Farinha 6.

Fernandes et al., (2013) estudaram os parâmetros de qualidade física e físicoquímica da farinha de mandioca (Manihot esculenta Crantz) durante o processamento e observaram que o aumento de acidez pode ocorrer por dois motivos principais, o primeiro é a fermentação das raízes (submetidas ao processo de produção), e o segundo é pela concentração dos ácidos devido ao processo de torragem.

Os valores médios para energéticos totais apresentaram faixas entre 342,58 e $361,48 \mathrm{Kcal} .100 \mathrm{~g}^{-1}$ para período 1/abril (P1) e 356,58 e 364,29 Kcal.100 $\mathrm{g}^{-1}$ para período 2/setembro (P2), os resultados podem ser observados na Tabela 3.

TABELA 3. Caracterização dos valores energéticos de farinhas de mandioca analisadas nos meses de abril e setembro (P1 e P2).

\begin{tabular}{|c|c|c|}
\hline \multirow{2}{*}{ Farinhas } & \multicolumn{2}{|c|}{ Valor Energético (Kcal. $100 \mathrm{~g}^{-1}$ ) } \\
\hline & P1 & P2 \\
\hline F1 & $346,58 \pm 0,02$ & $356,58 \pm 0,05$ \\
\hline F2 & $342,58 \pm 0,09$ & $357,54 \pm 1,01$ \\
\hline F3 & $361,48 \pm 0,16$ & $360,96 \pm 0,08$ \\
\hline F4 & $354,62 \pm 0,03$ & $356,84 \pm 0,01$ \\
\hline F5 & $357,70 \pm 0,03$ & $363,30 \pm 0,06$ \\
\hline F6 & $359,76 \pm 0,01$ & $364,29 \pm 0,05$ \\
\hline
\end{tabular}

Legenda: F1 = Farinha 1, F2 $=$ Farinha 2, F3 = Farinha 3, F4 = Farinha 4, F5 = Farinha 5 e F6 = Farinha 6.

Grande parte dos valores energéticos encontrados neste trabalho, assimilaram-se aos resultados encontrados por Álvares et al., (2016), que foi de 358,32 a $388,36 \mathrm{Kcal} .100 \mathrm{~g}^{-1}$. As variações entre as amostras podem ser explicadas pela forma de extração da fécula de mandioca, indicando que a padronização do processo de produção artesanal da farinha de mandioca é de fundamental importância para a qualidade do produto final (ÁLVARES et al., 2016).

Quanto a avaliação da análise colorimétrica das farinhas de mandioca (Tabela 4), contatou-se variação entre os valores médios dos componentes de cor $L^{*}, a^{*} e$ $b^{*}$. O parâmetro $L^{*}$ representa a luminosidade, que varia do 0 (preto) ao 100 (branco). No presente trabalho o componente $L^{*}$ (luminosidade ou brilho), variou de 77,97 a 90,39 para o período 1 (P1) e 88,00 a 94,25 para o período 2 (P2), ou seja, as farinhas podem ser caracterizadas como claras, pois apontam tendência ao branco. 
TABELA 4. Valores médios dos parâmetros colorimétricos $\left(L^{*}, a^{*}\right.$ e $\left.b^{*}\right)$ de amostras de farinhas de mandioca coletadas nos meses de abril e setembro (P1 e P2).

\begin{tabular}{lcccccc}
\multirow{2}{*}{ Farinhas } & \multicolumn{5}{c}{$\mathbf{P 1}$} & \multicolumn{2}{c}{$\mathbf{P 2}$} \\
\cline { 2 - 7 } & $\mathbf{L}^{*}$ & $\mathbf{a}^{*}$ & $\mathbf{b}^{*}$ & $\mathbf{L}^{*}$ & $\mathbf{a}^{*}$ & $\mathbf{b}^{*}$ \\
\hline F1 & $86,25 \pm 0,12$ & $0,30 \pm 0,01$ & $12,07 \pm 0,10$ & $92,97 \pm 0,14$ & $0,44 \pm 0,02$ & $10,60 \pm 0,11$ \\
F2 & $83,06 \pm 0,06$ & $1,59 \pm 0,04$ & $16,94 \pm 0,16$ & $88,00 \pm 0,21$ & $2,12 \pm 0,14$ & $20,33 \pm 0,14$ \\
F3 & $77,97 \pm 0,21$ & $2,82 \pm 0,02$ & $17,33 \pm 0,28$ & $90,75 \pm 0,29$ & $1,60 \pm 0,05$ & $16,30 \pm 0,11$ \\
F4 & $81,01 \pm 1,94$ & $2,11 \pm 0,27$ & $16,78 \pm 0,54$ & $88,53 \pm 0,26$ & $2,59 \pm 0,04$ & $16,25 \pm 0,96$ \\
F5 & $80,66 \pm 0,88$ & $1,59 \pm 0,09$ & $16,74 \pm 0,32$ & $90,85 \pm 0,56$ & $1,66 \pm 0,10$ & $6,43 \pm 0,12$ \\
F6 & $90,39 \pm 0,46$ & $1,66 \pm 0,10$ & $16,86 \pm 0,19$ & $94,25 \pm 0,16$ & $1,26 \pm 0,06$ & $16,72 \pm 0,14$ \\
\hline
\end{tabular}

Legenda: F1= Farinha 1, F2 = Farinha 2, F3 = Farinha 3, F4 = Farinha 4, F5 = Farinha 5 e F6 = Farinha 6.

O parâmetro $a^{*}$ representa a variação de cor do verde ao vermelho, valores de $\mathrm{a}^{*}<0$ indicam maior participação da cor verde $\mathrm{e} \mathrm{a}^{*}>0$ mais voltado para 0 vermelho. Neste estudo, todas as amostras de farinha de mandioca apresentaram os valores do croma $\mathrm{a}^{*}$ tendendo ao vermelho, uma vez que os mesmos apresentaram resultados $>0$, já o do croma $b^{*}$ com tendência ao amarelo. Dias et al., (2006), analisando cor em farinhas de mandioca de diversas classificações, observaram luminosidade $L^{*}$ variável de 78,43 a 92,8, croma a* variando de $-6,33$ a 4,10 e croma $b^{*}$ de 6,33 a 38,5 .

Os menores valores de luminosidade e maiores valores de coordenadas de cromaticidade $a^{*}$ e $b^{*}$, foram observados nas amostras F3 do período 1 (P1) e F2 e F4 do período 2 (P2). Esses parâmetros indicam a coloração mais escura (vermelho e amarelo) que as farinhas apresentam o que demonstra que as amostras dispõem de maiores teores de cinzas e fibras (FIORDA et al., 2013).

Já a análise granulométrica é um parâmetro de qualidade importante na padronização de produtos farináceos que são elaborados de modo artesanal. Dessa forma, a atual legislação descreve que a farinha de mandioca do Grupo Seca, pode ser classificada em três classes, sendo: a) fina: quando $100 \%$ do produto passar através da peneira com abertura de malha de $2 \mathrm{~mm}$ e ficar retida em até $10 \%$, inclusive, na peneira com abertura de malha de $1 \mathrm{~mm}$; b) grossa: quando o produto fica retido em mais de $10 \%$ na peneira com abertura de malha de $2 \mathrm{~mm}$; e c) média: quando a farinha de mandioca não se enquadrar em nenhuma das classes anteriores (BRASIL, 2011). A Tabela 5 apresenta os resultados das análises granulométricas.

TABELA 5. Valores médios percentuais da granulometria das amostras de farinha de mandioca coletadas nos meses de abril e setembro (P1 e P2).

\begin{tabular}{ccccccc} 
& \multicolumn{2}{c}{ Peneira de malha 2mm } & \multicolumn{2}{c}{ Peneira de malha 1 mm } & \multicolumn{2}{c}{ Classificação } \\
\cline { 2 - 4 } Farinhas & \multicolumn{2}{c}{ (\%) Retenção } & \multicolumn{2}{c}{ (\%)Retenção } & & \\
\cline { 2 - 4 } & $\mathbf{P 1}$ & $\mathbf{P 2}$ & $\mathbf{P 1}$ & $\mathbf{P 2}$ & P1 & P2 \\
\cline { 2 - 4 } F1 & $2,12 \pm 0,27$ & $1,21 \pm 0,04$ & $23,08 \pm 3,90$ & $16,70 \pm 0,65$ & Média & Média \\
F2 & $2,43 \pm 0,35$ & $4,74 \pm 0,42$ & $23,12 \pm 2,21$ & $25,62 \pm 3,28$ & Média & Média \\
F3 & $1,07 \pm 0,16$ & $1,40 \pm 0,13$ & $21,53 \pm 2,28$ & $18,45 \pm 0,65$ & Média & Média \\
F4 & $1,24 \pm 0,11$ & $3,37 \pm 0,13$ & $23,03 \pm 1,74$ & $17,46 \pm 1,15$ & Média & Média \\
F5 & $3,40 \pm 0,04$ & $1,40 \pm 0,11$ & $15,89 \pm 0,57$ & $17,54 \pm 1,72$ & Média & Média \\
F6 & $0,95 \pm 0,19$ & $1,24 \pm 0,14$ & $18,12 \pm 2,61$ & $13,63 \pm 1,03$ & Média & Média
\end{tabular}

Legenda: F1 = Farinha 1, F2 = Farinha 2, F3 = Farinha 3, F4 = Farinha 4, F5 = Farinha 5 e F6 = Farinha 6. 
De acordo com o que é preconizado pela Instrução Normativa $n^{\circ} 52$, de 8 de novembro de 2011 (BRASIL, 2011), constata-se pela Tabela 5 que todas as amostras de farinha de mandioca foram classificadas como "média". A microscopia de alimentos é uma técnica microanalítica que pode ser utilizada como ferramenta de controle de qualidade de bebidas e objetiva identificar principalmente matérias estranhas físicas e sujidades (fragmentos de origem animal), permitindo constatar se o material analisado está adequado em relação à legislação (BARBIERI, 2001).

As matérias estranhas são definidas como qualquer material não constituinte do produto associado a condições ou práticas inadequadas. A atual legislação sobre microscopia de alimentos classifica matérias estranhas em dois grupos, sendo: i) indicativas de riscos à saúde humana (capazes de veicular agentes e/ou causar danos ao consumidor) abrangendo as formigas, baratas, roedores, pombo, morcego e, ii) indicativas de falhas das Boas Práticas de Fabricação, abrangendo os artrópodes, pelos humanos, fungos filamentosos, areia, terra, entre outros (BRASIL, 2014).

Embora a Instrução Normativa $\mathrm{n}^{\circ}$ 52, de 8 de novembro de 2011 (BRASIL, 2011), que estabelece as características de identidade e qualidade da farinha de mandioca, não caracterize padrões para produtos farináceos artesanais, para a pesquisa microscópica foi feita uma analogia com farinhas de mandioca do Grupo Seca, que devem apresentar ausência de matérias estranhas em um kg de amostra. Os valores médios dos resultados para a pesquisa de matérias estranhas podem ser observados na Tabela 6.

TAELA 6. Pesquisa de matérias estranhas em amostras de farinhas de mandiocas artesanais provenientes do município de Santana de Pirapama/MG.

\begin{tabular}{lll}
\hline \multirow{2}{*}{ Tipos de Sujidades } & \multicolumn{2}{l}{ Amostras com sujidades } \\
\cline { 2 - 3 } & P1 & P2 \\
\hline Fragmentos de insetos & F1, F2, F3, F4, F5 e F6 & F2, F4 e F6 \\
Insetos inteiros & F4 & F1 e F4 \\
Fibras de Tecido & F3 e F4 & F4, F5 e F6 \\
Pelo & F1, F2, F5 e F6 & F2 \\
Resíduo metálico & F4 & ${ }^{*}$ N.I. \\
Ácaro & F4 & ${ }^{*}$ N.I. \\
Pelo de Rato & F3 & F6 \\
\hline
\end{tabular}

Legenda: F1 = Farinha 1, F2 = Farinha 2, F3 = Farinha 3, F4 = Farinha 4, F5 = Farinha 5 e F6 = Farinha 6.

${ }^{*} N . I .=$ não identificado.

No presente estudo, foram identificadas matérias estranhas em $90 \%$ das farinhas analisadas, com exceção da amostra F3 do período 2 (P2). Em 100\% das amostras do período 1(P1) foram encontrados fragmentos de insetos, em contrapartida no período 2 (P2) essas sujidades leves foram identificadas apenas nas amostras F2, F4 e F6. A presença de fragmentos de insetos é indicativa de falhas das Boas Práticas de Fabricação dos produtos (BRASIL, 2014) e sugere contaminações durante o processamento das mesmas (CARDOSO FILHO et al., 2015). Além disso, foram identificadas fibras de tecidos nas amostras F3 e F4 do período 1 (P1) e F4, F5 e F6 do período 2 (P2).

Nas amostras F3 do período 1 (P1) e F6 do período 2 (P2), foram encontrados pelos de rato, e nas amostras F4 do período 1 (P1), F1 e F4 do período 2 (P2), foram identificados insetos inteiros. A RDC $n^{\circ} 14$ de março de 2014, 
estabelece que a presença de materiais de origem animal, como roedores (rato, ratazana e camundongo), inteiros ou em partes, bem como insetos (baratas, formigas, moscas e barbeiros), vivos ou mortos, inteiros ou em partes são matérias estranhas indicativas de riscos à saúde humana, capazes de veicular agentes patogênicos para os alimentos e/ou de causar danos a saúde do consumidor (BRASIL, 2014).

Ademais, foi identificado na amostra F4 do período 1 (P1) a presença de ácaro e resíduos metálicos. Os resíduos metálicos encontrados são derivados de colheres ou do tacho utilizado no processo de torração da farinha de mandioca. Já o consumo de produtos farináceos com a presença de ácaros pode causar distúrbios gastrointestinais, dermatites e outros tipos de fenômenos alérgicos, especialmente respiratórios (CARDOSO FILHO et al., 2015).

Com exceção da amostra F3 do período 2 (P2), as demais farinhas não atenderam ao previsto pela Legislação Brasileira, uma vez que esta estabelece ausência de qualquer matéria estranha em produtos farináceos (BRASIL, 2011). As Figuras 1, 2, 3, 4, 5, 6 e 7 estão representando algumas sujidades encontradas nas amostras analisadas.

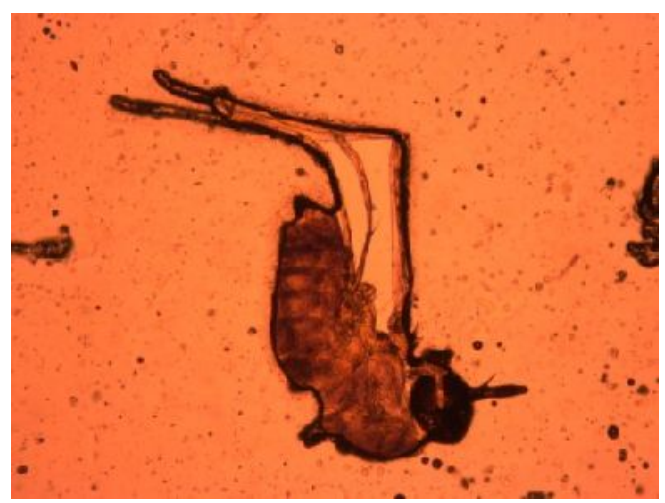

Figura 1 Inseto não identificado em amostra de farinha de mandioca (40X). Fonte: Autoria Própria

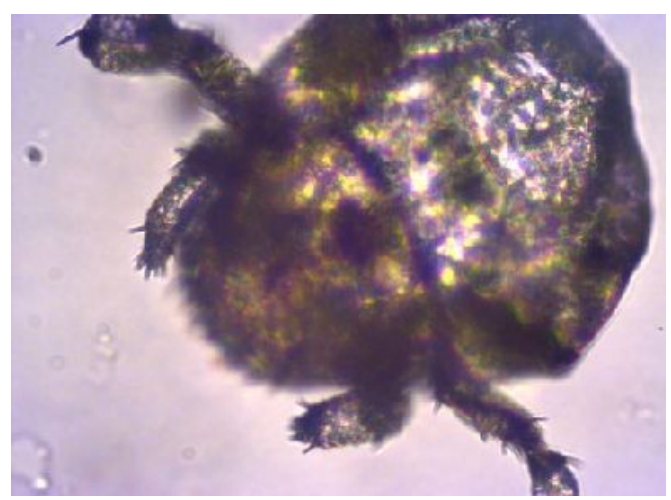

Figura 3 Ácaro em amostra de farinha de mandioca (400X).

Fonte: Autoria Própria

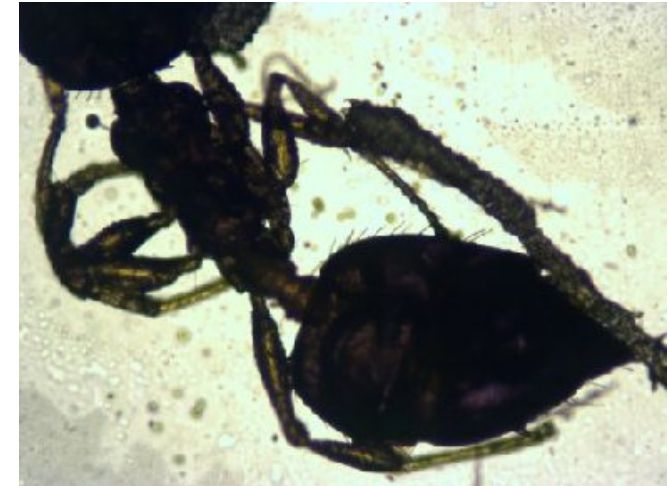

Figura 2 Formiga encontrada em amostra de farinha de mandioca (40X). Fonte: Autoria Própria

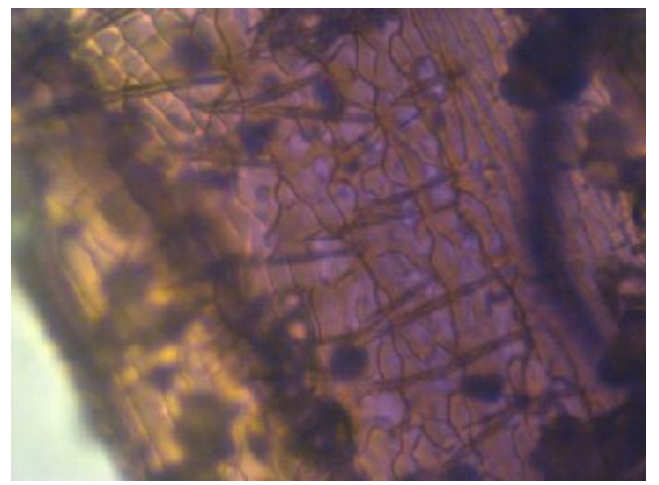

Figura 4. Parte do fragmento de inseto identificado em amostra de farinha de mandioca (400X).

Fonte: Autoria Própria 


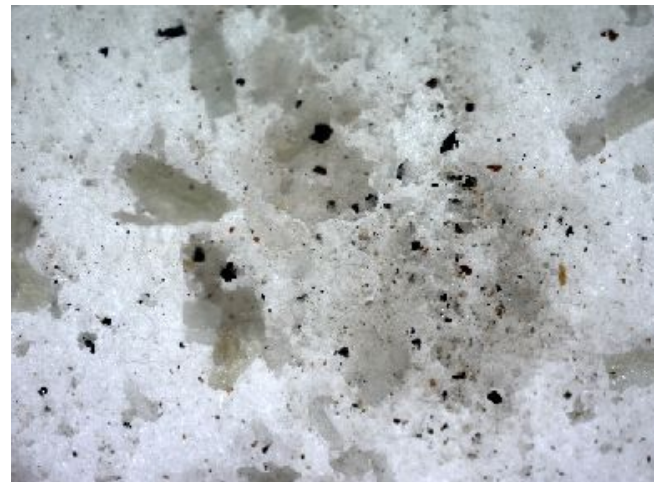

Figura 5 Resíduos metálicos identificados em amostra de farinha (15X).

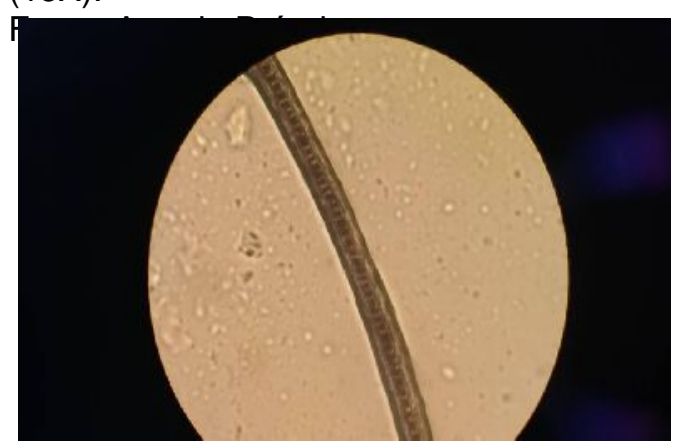

Figura 7 Pelo de rato em amostra de farinha de mandioca (100X).

Fonte: Autoria Própria

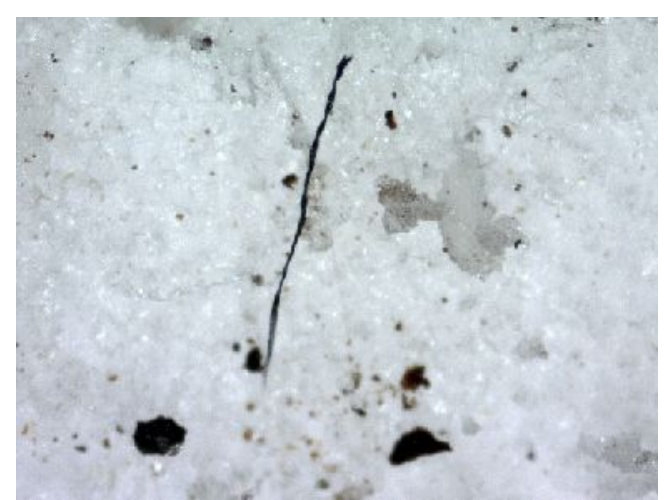

Figura 6 Fibra de tecido encontrada em amostra de farinha (50X).

Fonte: Autoria Própria

As análises microbiológicas foram realizadas com o intuito de avaliar as condições de acondicionamento das farinhas de mandioca, dessa forma, foi realizada a contagem de bolores e leveduras, conforme apresentado na Tabela 7.

TABELA 7: Análise microbiológica de amostras de farinhas de mandiocas artesanais provenientes do município de Santana de Pirapama/MG.

\begin{tabular}{llll}
\hline Farinhas & Microorganismos & P1 & P2 \\
\hline F1 & & $<10$ & $1 \times 10^{2}$ \\
F2 & Bolores e Leveduras $^{-1}$ & $<10$ & $<10$ \\
F3 & ${\text { UFC. } g^{-1}}^{2}$ & $4,0 \times 10^{2}$ & $<10$ \\
F4 & & $1,5 \times 10^{2}$ & $2 \times 10^{2}$ \\
F5 & $<10$ & $1 \times 10^{2}$ \\
F6 & & $<10$ & $1 \times 10^{2}$ \\
\hline
\end{tabular}

Legenda: $F 1=$ Farinha $1, F 2=$ Farinha 2, F3 = Farinha 3, F4 = Farinha 4, F5 = Farinha 5 e F6 = Farinha 6.

As amostras F3 e F4 no período 1 (P1) e F1, F4, F5 e F6 no período 2 (P2) apresentaram resultados de $4,0 \times 10^{2}$ UFC. $g^{-1}, 1,5 \times 10^{2}$ UFC. $g^{-1}, 1,0 \times 10^{2}$ UFC. $g^{-1}$, $2 \times 10^{2}$ UFC. $\left.g^{-1}\right), 1 \times 10^{2}$ UFC. $g^{-1}$ ) e $1 \times 10^{2}$ UFC. $g^{-1}$, respectivamente. As amostras que apresentaram maior crescimento de colônias foram a F3 do período 1 (P1) e F4 do período 2 (P2). As farinhas de mandioca artesanais na maioria são armazenadas em sacos plásticos (nylon), e acondicionadas em bancadas de madeira. Esse fato 
faz com que as mesmas, fiquem expostas as condições ambientais por um período muito longo o que contribui para a multiplicação de microrganismos (SILVA et al., 2017).

O período e condições inadequadas de armazenamento podem favorecer o desenvolvimento de microrganismos, além da forma de comercialização da farinha, que normalmente ocorre em sacos de $50 \mathrm{~kg}$ abertos em contato direto com o ambiente (RODRIGUES et al., 2015).

Souza et al. (2015) avaliaram a qualidade microbiológica da farinha de mandioca comercializada na região sudoeste da Bahia e observaram a presença de bolores e leveduras em $100 \%$ das farinhas analisadas. Neste estudo, foram analisadas cinco amostras diferentes, sendo que três apresentaram maior contaminação por bolores e leveduras, com resultados que atingiram entre $1,7 \times 10^{3}$ $\mathrm{UFC} / \mathrm{g}^{-1}$ e $2,2 \times 10^{4}$.

Rodrigues et al. (2015) também avaliaram a presença de bolores e leveduras em farinhas de mandioca comercializadas no Paraná e encontraram diferenças em seus resultados que variaram de $<1,0 \times 10^{1}$ UFC.g ${ }^{-1}$ a $3 \times 10^{3}$ UFC.g ${ }^{-1}$. No presente estudo, as amostras de farinhas foram coletadas em uma cidade que se encontra na região do Cerrado, a qual apresenta altas temperaturas e baixa taxa de umidade, estes fatores podem ter contribuído para os resultados encontrados, visto que esses tipos de microrganismos (bolores e leveduras) são capazes de se desenvolverem em alimentos que apresentam baixa umidade e baixa atividade de água $(A w<0,60)$, como é o caso da farinha de mandioca (RODRIGUES et al., 2015).

\section{CONCLUSÕES}

As amostras coletadas não apresentaram diferenças importantes em relação as análises físico-químicas e nutricionais, atendendo, portanto, aos padrões de qualidade exigidos pela Legislação Brasileira quanto a esses parâmetros.

A pesar da baixa contagem de bolores e leveduras nas amostras de farinha, a presença de matérias estranhas evidencia como a forma de produção tem influências direta na qualidade do produto final.

Boas práticas de fabricação e uma maior fiscalização quanto a qualidade das farinhas de mandioca, pode proporcionar uma redução das irregularidades no processo produtivo e de distribuição, além de oferecer maior segurança alimentar para o consumo desse produto.

\section{REFERÊNCIAS}

AOAC. Association of Official Analytical Chemists. Official Methods of Analysis of AOAC International, 20th Edition, Gaithersburg, USA, 2016.

ÁLVARES, V. S.; MIQUELONI, D. P.; NEGREIROS, J. R. S. Variabilidade físicoquímica da farinha de mandioca do Território da Cidadania do Vale do Juruá, Acre ${ }^{1}$. Revista Ceres, Viçosa, v. 63, n.2, p. 113-121, 2016. Disponível em: http://dx.doi.org/10.1590/0034-737X201663020001. doi: 10.1590/0034737X201663020001

BARBIERI, M. K. Microscopia em alimentos: identificação histológica e material estranho. ITAL. São Paulo. 2001. 
BRASIL. MAPA. Ministério da Agricultura, Pecuária e Abastecimento. Resolução RDC $n^{\circ}$ 52, de 07 de novembro de 2011. Aprova o Padrão oficial de classificação da farinha de mandioca, considerando seus requisitos de identidade e qualidade, a amostragem, o modo de apresentação e a marcação ou rotulagem, nos aspectos referentes à classificação do produto. Diário Oficial [da] República Federativa do Brasil, 2011. Disponível em: < http://www.agricultura.gov.br> Acesso em: em 28 de outubro de 2018.

BRASIL. MAPA. Ministério da Agricultura, Pecuária e Abastecimento. Resolução RDC $n^{\circ}$ 14, de 28 de março de 2014. Dispõe sobre matérias estranhas macroscópicas e microscópicas em alimentos e bebidas, seus limites de tolerância e dá outras providências. Diário Oficial [da] República Federativa do Brasil, 2014. Disponível em: http://bvsms.saude.gov.br/bvs/saudelegis/anvisa/2014/rdc0014_28_03_2014.pdf> Acesso em: em 28 de outubro de 2018.

CARDOSO FILHO, N.; SILVA, L. A.; DE LIMA, C. A.; \& ARANDIA, G. O. A. Caracterização da farinha de mandioca comercializada no Mercado Municipal em Campo Grande-MS. Ensaios e Ciência: C. Biológicas, Agrárias e da Saúde, v. 16, n. $\quad 5,2015.2$ Disponível em: < http://revista.pgsskroton.com.br/index.php/ensaioeciencia/article/view/2760>. doi: < http://dx.doi.org/10.17921/1415-6938.2012v16n5p\%25p>.

DIAS, L. T.; LEONEL, M. Caracterização físico-química de farinhas de mandioca de diferentes localidades do Brasil. Ciência e Agrotecnologia, p. 692-700, 2006. Disponível em: <http://dx.doi.org/10.1590/S1413-70542006000400015.> doi: $<10.1590 /$ S1413-70542006000400015>.

DIMOV, M. N.; SILVEIRA, V. R.; ELIAN, S. N.; PENTEADO, M. D. V. C. Extração de sujidades leves em farinha de trigo integral: validação de metodologia. Rev. Inst. Adolfo Lutz, v. 63, n. 1, p. 91-96, 2004. Disponível em: < http://ses.sp.bvs.br/lildbi/docsonline/get.php?id=421>. < doi: 10.5073/jka.2010.425.167.059>.

EMBRAPA - Empresa Brasileira de Pesquisa Agropecuária. Mandioca. Brasília, 2016. Disponível em: <https://www.embrapa.br/mandioca-efruticultura/cultivos/mandioca>. Acesso em: 05 de janeiro de 2019.

FERNANDES, H. R.; DE OLIVEIRA, D. C. R.; SOUZA, G. S.; LOPES, A. S. Parâmetros de Qualidade física e físico-química da farinha de mandioca (Manihot esculenta Crantz) durante processamento. Scientia Plena, v. 9, n. 11, 2013. Disponível em: < https://www.scientiaplena.org.br/sp/article/view/1615/917>.

FIORDA, F. A.; JUNIOR, M. S. S.; SILVA, F. A.; SOUTO, L. R. F.; GROSSMANN, M. V. E. Farinha de bagaço de mandioca: aproveitamento de subproduto e comparação com fécula de mandioca. Pesquisa Agropecuária Tropical (Agricultural Research in the Tropics), v. 43, n. 4, p. 10-1590, 2013. Disponível em: < https://www.revistas.ufg.br/pat/article/view/23381/15577>. doi: < 10.1590/S198340632013000400005>. 
GIACOMELLI, D.; MONEGO, B.; DELAGUSTIN, M. G.; BORBA, M. M.; RICALDE, S. R.; FACCO, E. M. P.; SIVIERO, J. Composição Nutricional das farinhas de milho pré-cozida, moída à pedra e da preparação culinária "Polenta". Brazilian Journal of Food \& Nutrition/Alimentos e Nutrição, v. 23, n. 3, 2012. Disponível em: < http://serv-bib.fcfar.unesp.br/seer/index.php/alimentos/article/viewFile/415/1857>.

IAL - Instituto Adolfo Lutz . Normas Analíticas do Instituto Adolfo Lutz: Métodos físico-químicos para análise de alimentos. São Paulo, 2008. $1^{\circ}$ Edição Digital. Disponível em:

http://www.crq4.org.br/sms/files/file/analisedealimentosial_2008.pdf> Acesso em: 28 de outubro de 2018.

MATTOS, P. L. P.; FARIAS, A. R. N.; FILHO, J. R. F. Mandioca: O Produtor pergunta, a Embrapa responde (Coleção 500 perguntas, 500 respostas). $1^{a}$ ed. Brasília, DF: Embrapa Informação Tecnológica, 2006.

OLIVEIRA, F.; JORGE, L. I. F.; RITTO, J. L. A.; BARROSO, I. C. E.; PRADO, B. W. Microscopia de Alimentos: Exames Microscópicos de Alimentos in Natura e Tecnologicamente Processado. p. 412. São Paulo: Atheneu, 2015.

RODRIGUES, E. B.; ARAÚJO, A. M.; SOBRAL, F. D. O. S.; ROMÃO, N. F. Avaliação da presença de bolores e leveduras em farinha de mandioca (Manihot esculenta Cratz) comercializadas a granel em feiras livres do município de JL-ParanáRO. South American Journal of Basic Education, Technical and Technological, v. 2, n. 2, 2015.2 Disponível em: < https://periodicos.ufac.br/index.php/SAJEBTT/article/view/372/203>.

SEAPA. Secretaria de Estado de Agricultura, Pecuária e Abastecimento. Relatórios da Agricultura. Disponível em: <http://www.agricultura.mg.gov.br/2014-09-23-01-0723/relatorios/agricultura>. Acesso em: 28 de outubro de 2018.

SILVA, M. J.; DE ARAÚJO, S. K. P. R.; DA SILVA, P. F. C. Análise micológica da farinha de mandioca vendida nas feiras dos produtores na cidade de MACAPÁAP. Revista Ciência e Sociedade, v. 1, n. 2, p. 103-112, 2017. Disponível em: < http://periodicos.estacio.br/index.php/cienciaesociedade/article/viewArticle/3601>.

SILVA, A. C. M. S.; PINHO, L. S.; SOUSA, L. S., MOURA, L. E.; DE SOUZA, C. O.; DRUZIAN, J. I. Classificação, identidade e matérias estranhas de farinha de mandioca Copioba: conformidade com a legislação brasileira e contribuição a indicação geográfica. Cadernos de Prospecção, v. 8, n. 1, p. 192, 2015. Disponível em: <http://dx.doi.org/ 10.9771/S.CPROSP.2015.001.022 > doi: 9771/S.CPROSP.2015.001.022

SILVA, N., JUNQUEIRA, V. C. A., SILVEIRA, N. F. A., TANIWAKI, M. H., SANTOS, R. F. S., GOMES, R. A. R. Manual de métodos de análise microbiológica de alimentos e água. 4⿳亠丷a edição. São Paulo: Varela, 624p, 2010. 
SIQUEIRA, N. P. N. C.; SILVA, C. Í. R.; ANDRADE, A. C. B., Conceição, C. G., SANTOS, DRUZIAN, J. I. Classificação, identidade e matérias estranhas de farinha de mandioca Copioba: conformidade com a legislação brasileira e contribuição a indicação geográfica. Cadernos de Prospecção, v. 8, n. 1, p. 192, 2015. Disponível em: <https://portalseer.ufba.br/index.php/nit/article/view/12335/pdf_93>. doi: 10.9771/S.CPROSP.2015.001.022

SOUZA, J. R.; FIGUEIREDO, R. M.; SANTANA, P. M. C. Qualidade Microbiológica da Farinha de Mandioca Comercializada na Região Sudoeste da Bahia. Revista Brasileira de Produtos Agroindustriais, v.17, n.2, p.117-123, 2015. Disponível em: $<$ http://www.deag.ufcg.edu.br/rbpa/rev172/Art1721.pdf>. doi: 10.15871/15178595/rbpa.v17n2p117-123 